\title{
Introducción bibliográfica al termalismo antiguo en la Península Ibérica *
}

\author{
F. Diez de Velasco \\ M. J. PEREXX \\ C. MIRÓ
}

0. GENERALIDADES

0.1. Bibliografia

MANDERSCheid, H., Bibliographie zum römischen Badewesen. Berlín 1988. Chevallier, R., «Bibliographie d'orientation», Les eaux thermales et les cultes des eaux en Gaule et dans les provinces voisines. Actes Coll. 28-30 septiembre 1990, Aix-les-Bains (R. Chevallier ed.). Tours-Turín 1992, págs. 453-468.

\subsection{Obras generales sobre termas y balnearios}

BRÖDNER, E., Die römische Thermen und das antike Badewesen. Darmstadt 1983.

HEINZ, W., Römische Thermen. Munich 1983.

* Esta recopilación no pretende ser exhaustiva. Se han seleccionado las obras más representativas, prescindiendo de los repertorios y referencias epigráficas, que harian innecesariamente larga esta relación. La bibliografía referida a Portugal y Francia, puede encontrarse acompañando los trabajos de $\mathrm{H}$. Frade y $\mathrm{B}$. Grangé, respectivamente. 
ChevallieR, R. (ed.), Les eaux thermales et les cultes des eaux en Gaule et dans les provinces voisines. Actes Colloque, 28-30 septiembre 1990. Aix-les-Bains, Tours-Turin 1992.

V.V. A.A., Les thermes romains. Actes de la table ronde organisée par l'Ecole Française de Rome (Rome 11-12 novembre 1988). Roma, EFR, 1991.

LETZNER, W., Römische Brunnen und Nymphaea in der westlichen Reichhälfte. Berlin 1990.

GESCHWENDt, F., Der Vor-und frühgeschichtliche Mensch und die HeilqueIlen. Hildesheim 1972.

GoRJux, J., Recherches sur les eaux thermales et minérales de l'Hellade, de l'talie et des Gaules aux temps anciens, Tesis. Burdeos 1913.

Nielsen, I., Thermae et Balnea. The architecture and cultural history of roman public baths. 1990, 2 vols.

Muthmann, F., Mutter und Quelle. Studien zur Quellenverehrung im Altertum und im Mittelalter. Mainz 1971.

\subsection{Vocabulario balnear}

Rebuffat, R., "Vocabulaire thermal: documents sur le bain romain», Les thermes romains, actes de la table ronde EFR, Rome 11-12 novembre 1988. EFR. Roma 1991, págs. 1-34.

\subsection{Toponimia}

CHAVES, L., "A toponimia das augas. As augas na toponimia portuguesa», $R G, 66,1956$, págs. 35-74.

PIEL, J., "As augas na toponimia gallego-portuguesa», Boletim de Filologia 8, 1947, págs. 305-342.

MILLAN, I., «Encuadramiento etimológico de la voz prelatina Burgas», EMP 37, 1983, págs. 407-420.

RofliN, M., "Hydrothérapie antique et toponymie», Médecine de France 43, 1969, págs. 3-10.

Chevalies, R., "Une source négligée des études sur les cultes de l'Antiquité: la toponymie. Recherches concernant les deux versants des Alpes», Caesarodunum, Comptes rendus XV, 1980, págs. 20-30. 


\subsection{Medicina antigua}

\subsubsection{Ejemplos extrapeninsulares y fuentes literarias}

Pelletier, A., (ed.), La médecine en Gaule. Villes d'eaux, sanctuaires des eaux. París 1985.

FontANILLe, M. T., "Les bains dans la médecine Gréco-romaine», La médecine en Gaule, págs. 15-24.

Bonnard, L.; Percepied, La Gaule thermale. Paris 1907.

RICHARD, M., Le thermalisme gallo-romain. Tesis en medicina. Burdeos 1968.

Boupdy, F., «Du bon usage des bains d'après Oribase», R. Chevallier (ed.), Les eaux thermales..., págs. 31-38.

GuIART, J., La Gaule et la médecine gauloise, les villes d'eau de la Gaule romaine. Paris 1938.

BlutEAU, A., Emploi thérapeutique des eaux potables et des eaux minérales dans l'antiquité gréco-romaine. Tesis en medicina. Burdeos 1931.

Brunies, Y., L'hydrologie de Pline l'Ancien. Tesis en medicina. Burdeos 1933.

Phelippaud, J. Y., Oribase et l'hydrologie au IVe siècle. Tesis en medicina. Burdeos 1935.

Pierrot, A. M., L'oeuvre hydrologique de Sénèque le philosophe. Tesis en medicina. Burdeos 1947.

BARTHE, M., Le thermalisme gallo romain dans les Pyrenées centrales. Tesis en medicina. París 1969.

APh rúbrica «médecine» y autores médicos (Oribasio, Galeno, Aecio, Celso, etc.) y de otro tipo (Vitrubio, Plinio, etc.).

\subsubsection{Medicina antigua y terapéutica termal en la Península Ibérica}

Leite de Vasconcellos, I., Medicina dos Lusitanos. Lisboa 1923.

MOLTO, L., «Aguas mineromedicinales en los yacimientos termales de Hispania», Les eaux thermales et les cultes des eaux en Gaule et dans les provinces voisines, Actes Colloque 28-30 septiembre 1990. Aix-les Bains, Tours-Turín 1992, págs. 117-132.

Zaragoza Rubira, J. R., "La medicina en la España Antigua», Cuadernos de Historia de la medicina española IV, 1965, págs. 131-189.

- Medicina y sociedad en la España Romana. Barcelona 1971. 


\section{ARQUEOLOGIA}

\subsection{Técnica constructiva}

\subsubsection{Generalidades y fuentes literarias}

MORTET, V., «Recheches critiques sur Vitruve et son oeuvre. IV Vitruve et I'hydraulique romaine", $R A$ IX, 1907, págs. 75-83.

Floriano, A., «Aportaciones arqueológicas a la historia de la medicina romana», AEArq 1941, págs. 429-433.

\subsubsection{Construcción balnear}

Adam, J. P., La construction romaine. Paris 1984, págs. 287-294.

GRENIER, A., Manuel d'archéologie gallo-romaine, IV les monuments des eaux, villes d'eaux et sanctuaires des eaux, III les thermes des villes d'eau. París 1960, págs. 401-474.

Brodner, E., Die Römische Thermen. Darmstadt 1983, págs. 18-23/155-162. LugLi, C., La técnica edilizia romana. Roma 1957.

Neuerburg, N., L'architettura delle fontane e dei ninfei. Nápoles 1965.

BIREBENT, A:, Aquae romanae. Recherches d'hydraulique romaine dans l'est algérien. Alger 1962.

\subsubsection{Técnicas de captación, hidráulica antigua}

Molliere, H., «Mémoire sur le mode de captage et l'aménagement des sources thermales de la Gaule romaine", Memoires de l'Académie des Sciences, Belles-Llettres et Arts de Lyon, 3e serie, París-Lyon 1893.

FERnANDEZ CASAdo, C., Ingeniería hidráulica romana. Madrid 1983.

Bonnin, J., L'eau dans l'antiquité. L'hydraulique avant notre ère. París 1984.

\subsection{Ejemplos de grandes balnearios extrapeninsulares}

Cueppers, H., Aquae Granni. Beiträge zur Archäologie von Aachen. Bonn 1982.

CUNLIFFE, B., Roman Bath discovered. Londres 1971.

-, Excavations in Bath 1950-1975. Oxford 1979.

Cunlife, B.; Davenport, P., The temple of Sulis Minerva at Bath. Oxford 1988. 
Tombin, R.; WalkeR, D., The temple of Sulis Minerva at Bath, 2. The Finds from the sacred spring. Oxford 1988.

Schallmayer, E., Aquae, das römische Baden-Baden. Stuttgart 1989.

DavenPort, P., (ed.), Archaeology in Bath 1976-1985, OUCA Monog. 28, 1991, 178 págs.

\subsection{Balnearios de la Península lbérica}

\subsubsection{Estudios generales}

DIEZ DE Velasco, F., Balnearios y divinidades de las aguas termales en la Peninsula Ibérica en época romana. Ed. en microficha. Madrid 1987, 456 págs.

MorA, G., "Las termas romanas en Hispania», AEArq, 54, 1981, págs. 3789.

CAssani, J. C., "Tres termas medicinales en la España romana», Cuadernos de Historia de España, 10, 1948, págs. 105 y sigs.

\subsubsection{Estudios zonales}

Dupré, N.; Peréx, M. J., «Termalisme et religion dans le Nord de l'Hispania", Les eaux thermales et les cultes des eaux en Gaule et dans les provinces voisines. Actes Colloque 28-30 septiembre 1990. Aix-lesBains, Tours-Turin 1992, págs. 151-169.

DIEZ DE VELASCO, F., «Balnearios y dioses de las aguas termales en Galicia romana", AEArq. 58, 1985, págs. 69-98.

-, «Divinités des eaux thermales dans le Nord-Ouest de la Prouincia Tarraconensis et dans le Nord de la Prouincia Lusitania: une approche au phénomène du thermalisme romain dans l'Occident des provinces ibériques", Les eaux thermales et les cultes des eaux en Gaule et dans les provinces voisines. Actes Colloque 28-30 septiembre 1990. Aix-les Bains, Tours-Turín 1992, págs. 133-149.

Frade, H., «As termas medicinais de época romana em Portugal», Actas do II Congresso Peninsular de Historia Antiga. Coimbra 1990 (en prensa).

\subsubsection{Estudios especificos}

Álvarez Martinez, J. M., "Las termas romanas de Alanje», Habis, 1972, 3, págs. 267-291.

- Alange y sus termas romanas. Badajoz 1973.

_, «Alange y sus termas romanas», Alminar, 1980, págs. 16-17. 
LANTIER, R., «Les bains romains d'Alanje», Bulletin Hispanique XVIII, 1916 , págs. 48-51.

Martínez, M., «Alanje», Revista de Extremadura II, 1900, págs. 405-415.

Villaescusa, J., Monografía de las aguas y baños minerales de Alange. Madrid 1850.

Puerto Rerna, J. A., Alange. Sevilla 1914.

MELIDA, J., «Las termas romanas de Alanje», Arquitectura III, 1920, págs. 122-128.

Saenz de BuruagA, J. A., "Alange», Alcántara VI, 1950, págs. 33-35.

SeRra Rafols, J. de C., «Las termas romanas de Caldas de Malavella», AEArq, núm. 43, 1944, págs. 301-315.

-, Las termas romanas de Caldas de Montbuy. Informes y Memorias, 32. Madrid 1956.

Botet y Sıso, J., «Aquis Voconis», Revista Histórica XXIII, 1876, págs. 7276.

Mıró, C., Excavacions a la Plaça de la Font del Lleó (Caldes de Montbui). Memòria de la intervenció d'urgència. Inèdita, 1986.

Miró, C., et alli, «El poblat ibèric de la Torre Rioja $i$ el conjunt termal de Caldes de Montbui (Vallès Occidental)", Tribuna d'Arqueologia 19871988. Barcelona, págs. 153-162.

-, "Les Termes romanes de Caldes de Montbui», ARRAONA, Sabadell 1992, págs. 11-30.

PitA, R., «Arties. Notas de Arqueología de Cataluña y Baleares II", Ampurias XXIV, 1962, pág. 322.

PITA, R., "Les. Notas de Arqueologia de Cataluña y Baleares», Ampurias XXVI-XXVII, 1964-65, págs. 300-301.

BARRY, E., «Les eaux thermales de Lez à l'époque romaine», Revue Archéologique, 1857, págs. 677-688.

Mezouiriz, M. A., "Las termas romanas de Fitero», Homenaje a J. M. Lacarra. Príncipe de Viana. Anejo 3, Pamplona 1986, págs. 539-554.

Medrano, M. A.; DiAZ, A. M., «Las instalaciones balnearias romanas de Fitero", I Congreso General Historia de Navarra (1986), t. 2. Pamplona 1987, págs. 491-501.

Beltrán Martínez, A., «Los hallazgos del balneario de Panticosa (Huesca)», Caesaraugusta, núm. 5, 1954, págs. 196 y sigs.

FERNÁNDEZ DE AvILÉS, A., «Prospección arqueológica en las Fontes Tamarici (Velilla, Palencia)", Revista de archivos, bibliotecas y museos, YIX, 1961, págs. 263-282.

López Cuevillas, F., «La mansio de Aquis Querquernis», BCMOrense VI, 1922 , págs. $416-430$.

RodRíguez Colmenero, A., "El campamento romano de Aquis Querquernis (Orense)», II Seminario de arqueología del noroeste. Santiago 1983. 
Gallego, O., «Los baños termales de Cerves, en Prexigueiro", Boletín Auriense XII, 1982, págs. 235-242.

Pesado Blanco, S., "Termas de Montemayor", Revista de Extremadura IV, 1902, págs. 263-270.

Morán Bardón, C., Los baños de Retortillo. Salamanca 1926.

Valiente, A., «Archena. Murcia», Noticiario Arqueológico Hispánico, núm. 287, 1952.

Moreira de Figueiredo, C. J., «As termas de S. Pedro do Sul», Actas e memorias do I Congresso Nacional de Arqueologia, vol. II. Lisboa 1970, págs. 57-68.

Vale, L., "Antiguidades do banho de S. Pedro do Sul», Beira Alta, 8(4), Viseu 1949, págs. 435-437.

Santos, E., dos: «As termas de S. Pedro do Sul. Elementos para a sua história», Beira Alta, 30(4). Viseu 1971, págs. 445-497.

-, «As termas de S. Pedro do Sul. Achegas para a sua história», Beira Alta, 26(4). Viseu 1967, págs. 477-514.

Almeida, Ferreira de, Thermas de S. Pedro do Sul (Caldas de Lafões). Porto 1930.

AzeVEDo, P. A., «Noticias archeologicas colhidas em documentos do seculo XVIII, 1. Ruinas das Caldas de Vizella», Archeologia Portuguesa, III, 1897, pág. 214.

LeITE DE VASCONDELLOS, J., «Balneario romano de Canaveses». O archeologo portugues VII, 1903, págs. 284-285.

Alves Pereira, F., «Bibliographia Il. Jose Fortes Junior-Balineum luso romano de S. Vicente de Pinheiro". O Archeologo Portugues VII, 1903, págs. 107-110.

FormosinHo et alii, Vestigios romanos nas Caldas de Monchique. Separata del I Congreso Español de Hidrología. Lagos 1948.

—, Estudios arqueológicos nas Caldas de Monchique. Porto 1953.

VIANA, A., «Notas de lexicografía arqueológica: Caldas de Monchique», Broteria LXI, págs. 162-165.

Lyster Franco, M., As termas romanas de Monchique. Faro 1945.

Carvalho, R., «O balneario romano La Quinta de Carvalhal Constancia Sul», Arqueologia, 15, 1987, págs. 116-121.

DIEZ DE VELASCO, F., "Ciudades de aguas (Aquae) y práctica balnear: el balneario galaico-romano de Aquae Querquernae (Baños de Bande)", en A. Rodríguez Colmenero (ed.) Excavaciones de Aquis Querquernis, Santiago 1993.

MAyer, M.; RodA, I., «La qüestió d'Aquae Calidae», Fonaments 5, 1985, págs. 182-185.

Garcia Romero, C., «Cuntis: memorias romanas», BRAG IX, 1916, págs. 273-278; X, 1917, págs. 289-292; XII, 1920, págs. 174-180. 
Lazaro, M., "Un Ninfeo romano en Jaén: la fuente de la Magdalena», I CPHA, Santiago 1988, págs. 341-351.

\section{EPIGRAFIA}

\subsection{Trabajos generales}

Véase 1.3.1., 1.3.2. y 3.3.2.

2.2. Trabajos especificos (excluidos los repertorios epigráficos generales, provinciales o locales)

RoldÁN, J. M., «Las lápidas votivas de Baños de Montemayor», Zephyrus, 16, 1965, págs. 5-37.

Lambrino, S., "La déesse Coventina de Parga», RFLetrLisboa 18, 1953, págs. 74-87.

Santos, J.; Cardozo, M., «Ex votos as Ninfas em Portugal», Zephyrus IV, 1953, págs. $53-68$.

Monteagudo, L., «Ara de Parga dedicada a Coventina», AEArq 20, 1947, págs. 68-74.

Ares VÁzouez, N., «En torno al ara Lucense a Cohvetene», Cuadernos de Estudios Gallegos XXII, 1967, págs. 157-164.

BrandaO, D., «Inscriçoes romanas do Balineum de Lafoes», Beira Alta 18, 1959, págs. 229 y sigs.

SaAvedRa, E., «Inscripción votiva de Boñar», Museo Español de Antigüedades II, 1873, págs. 599-601.

MontAL Y BIOSCA, A., "Caldas de Mombuy, sus aguas termales e inscripciones romanas en 1790", BRAH, 1907, págs. 129-143.

González Blanco, A. (ed.), Las inscripciones de la Cueva Negra (Fortuna, Murcia). Murcia 1990.

GonzÁlez Blanco, A. (y otros), "Las inscripciones romanas de la Cueva Negra (Fortuna, Murcia)», MHA III, 1978, págs. 277-284.

3. DIVINIDADES TERMALES Y CULTO A LAS AGUAS

\subsection{Generalidades}

Díez, E., «Quellnymphen», Festschrift Neutsch 1980, págs. 103-108. 
Muthmann, F., Mutter und Quelle, Mainz 1971.

WILD, R. A., Water in the Cultic Worship of Isis and Serapis. Leiden EPRO 87, 1981.

Croon, J. H., The Herdsman of the Death. Utrecht 1952.

Ginouves, R., Balaneutike. Paris 1962.

\subsection{Ejemplos extrapeninsulares importantes}

LE GLAY, M., «Coventina». LIMC III, 1, 1986, pág. 306.

VaILLAT, C., Le culte des sources dans la Gaule antique. Paris 1932.

VAUTHEY, M. et VautheY, P., «Borvo et le panthéon gallo-romain», OGAM XI, 1959, págs. 445-468.

Belfaida, A., Le culte des divinités des eaux en Afrique du Nord en époque romaine. Tesis de la Universidad de Burdeos III.

BAUCHNESS, G., "Apollo Borvo (Bormo, Bormanus, Bormanicus)", LIMC II, 1, 1984, págs. $460-461$.

Bourgeols, C., Divona: divinités et exvoto du culte gallo-romain de l'eau. Lille 1991.

DEYTS, S., Les bois sculptés des sources de la Seine. Gallia, supl. 42, 1983. Troisgros, H., Borvo et Damona. Bourbonne-le-Bains, 1975.

Croon, J. H., "The Cult of Sul-Minerva at Bath", Antiquity 27, 1953, 79-83 (también Cunliffe en 1.2).

Sobel, H., Hygieia. Berlin 1990.

Croissant, F., «Hygieia», LIMC V, págs. 554-572.

3.3. Culto a las aguas y culto a las aguas termales en la P.I.

\subsubsection{Culto a las aguas}

BLÁzquez, J. M., «El culto a las aguas en la Península Ibérica», Imagen y mito. Estudios sobre las religiones mediterráneas e ibéricas. Madrid 1977, págs. 307-330, traducción de «Le culte des eaux dans la Péninsule Ibérique», OGAM 9, 1957, 209-233.

Garcia Fernández Albalat, B., "Las Ilamadas divinidades de las aguas» en Bermejo, J. C., Mitología y mitos de la Hispania prerromana II. Madrid 1986, págs. 141-192.

Bouza Brey, F., La mitología del agua en el noroeste hispánico. Vigo 1973. LOPEZ CuevilLas, F., "O culto das fontes no Noroeste hispanico», Trabalhos da sociedade Portuguesa de Antropologia y Etnologia, VII, 1935, págs. 73-104. 
VAZQUEZ Hors, A.M., "Cultos y ritos de fecundidad y su simbologia: las aguas en la Hispania romana", Universidad y Sociedad, 1. UNED. Madrid 1981, págs. 167-181.

\subsubsection{Cultos termales}

Diez DE Velasco, F., Balnearios y divinidades de las aguas termales en la Península Ibérica en época romana. Madrid, 1987, págs. 28-101.

-, «Invocaciones a Isis en ciudades de aguas - Aquae- del occidente romano", Homenaje a A. Álvarez de Miranda. Madrid 1992, págs. 153162.

-, "Divinidades indixenas das augas termais no extremo occidente hispano", Larouco, 1, 1991, 53-60.

MiLLÁN, I., «Edovio», AEArq 38, 1985, págs. 50-54.

MARTINS SARMENTO, F., "O deus Bormanico" $R G$ I, 1884, págs. 57-87.

SANTOS, J. y CARDozo, M., "Ex votos as Ninfas em Portugal», Zephyrus IV, 1953, págs. 53-68.

\subsubsection{Iconografía}

Solana, J. M., «Precisiones sobre la patera argéntea de Otañes», Durius 5, 1977, págs. 139-145 (con bibliografía anterior).

BARATTE, F., "La coupe en argent de Castro Urdiales", Les eaux thermales et les cultes des eaux en Gaule et dans les provinces voisines. Actes Colloque 28-30 septiembre 1990. Aix-les-Bains, Tours-Turin 1992, págs. $43-54$.

Díez y PlatAS, F., Catálogo e iconografía de las Ninfas en la Hispania romana. Madrid 1987 (ed. en microficha). 